\title{
Spirometry in primary care in a region of Northern Norway - before and after a brief training course
}

\author{
Stein Johansen*
}

\author{
Department of Internal Medicine, Hålogalandssykehuset, Narvik, Norway
}

Received 1st November 2006; accepted 16th January 2007

\section{KEYWORDS \\ Spirometry; \\ COPD; \\ Diagnosis; \\ Training; \\ Primary care; \\ Referrals}

\begin{abstract}
Summary
A short, decentralised 13-hour training course on COPD and spirometry was delivered to primary care doctors and their assistants. The percentage of general practitioner (GP) referral letters - on patients with suspected peripheral airways disease - which contained information about FVC and FEV 1 increased from $9 \%$ before, to $56 \%$ after, the training course.

(c) 2007 General Practice Airways Group. All rights reserved.
\end{abstract}

\section{Introduction}

Early detection and intervention can alter the course and outcome of chronic obstructive pulmonary disease (COPD). ${ }^{1}$ However, diagnosis based on symptoms and signs alone seems to be insufficient $^{2}$ and the use of a spirometer is mandatory. ${ }^{3}$ Reports from Australia ${ }^{4}$ and the United Kingdom ${ }^{5}$ show that few primary care practices have access to office spirometry. It was our impression that the situation is similar in Norway.

Thus, we decided to find out if one could increase general practitioners' (GPs') use of spirometry in patients with suspected peripheral airways disease, by performing a brief training course. The study was part of a broad, local strategy which aimed to improve the cooperation between specialist and primary care services in our region.

\footnotetext{
* Corresponding author.

Dept of Internal Medicine, Hålogalandssykehuset, Narvik, Sykehusveien 3, 8516 Narvik, Norway

Tel: + 47 76968520; fax: + 4776968551

E-mail address: stein.johansen@hhf.no
}

\section{Methods}

Physicians, nurses, and health secretaries from six peripherally-located community health practices in the Ofoten region of North Norway were invited to participate in a brief training programme focusing on spirometry and COPD. The course consisted of three evening sessions of three hours each, separated by two work periods of two months, and 11 months, respectively. The programme concentrated on spirometry, the detection and assessment of COPD, and therapy for patients with COPD. In addition, within one to two days after the initial training session, the participants received a fourhour practical spirometry instruction session.

The training course was provided by the local community hospital pulmonologist, was crossprofessional, and took place in the local community itself. The programme content for sessions 1 (December 2002), 2 (February 2003), and 3 (January 2004), is shown in Boxes $1-3$.

The spirometry instruction session, based on recommendations from the American Thoracic Society, ${ }^{6}$ was carried out at the participants' 


\begin{tabular}{ll} 
Box $1 \quad$ Content of Session 1 \\
\hline Trial background, & purpose and design \\
COPD & Clinical picture \\
& Natural course \\
& GOLD classification \\
& Early diagnosis \\
& Treatment \\
& To inform about drug inhalation \\
Spirometry & Calibration \\
& Performance \\
& Interpretation \\
& Obstructive pattern
\end{tabular}

workplace. Standardised spirometric equipment (Vitalograph Alpha III spirometer, Nor Med AS, Oslo) was used during the study.

\section{Results}

The training programme was completed by personnel from five practices. The remaining practice participated in session 1 and at the spirometry instruction session only, and personnel from that practice were therefore excluded from the study.

At sessions 1, 2, and 3, and at the spirometric training session, there were $33,20,14$ and 39 participants, respectively. GPs from all five practices attended every session.

A diagnosis of peripheral airways disease ${ }^{7}$ was recorded following 148 consultations at the pulmonary outpatient clinic at the local community hospital, following elective referrals from the primary healthcare centres between 1 January 2001 and 28 February 2005. The referral letters from 139 of these consultations were identified. Nine letters were not found.

Results of primary care office spirometry including forced vital capacity (FVC) and forced expiratory volume during the first second $\left(\mathrm{FEV}_{1}\right)$ values - appeared in four out of 43 referrals (9\%) written before the training course, and in 14 out of 25 referrals (56\%) written after the training course.

Data were collected from a control group which comprised referrals from GPs at the remaining nine offices in the same geographical area who did not receive the brief training course. The corresponding figures for the presence of $\mathrm{FEV}_{1}$ and FVC values in the referral letters were 10 out of 39 (25.6\%) and 11 out of $32(34.4 \%)$, respectively.

\begin{tabular}{l} 
Box $2 \quad$ Content of Session 2 \\
\hline Spirometry. Revision on important subjects \\
GOLD classification \\
Whom to screen? \\
How to quit smoking? \\
How to inform about drugs? \\
\hline
\end{tabular}

\section{Box 3 Content of Session 3}

Reversibility test

To treat COPD exacerbation

Revision on important subjects

\section{Discussion}

The present study suggests that there is low access to office spirometry in this region of Norway, as has been shown in earlier studies from Australia ${ }^{4}$ and the UK. ${ }^{5}$ Basically, as few as $9 \%$ of the referrals prior to the training course gave information on FVC and $\mathrm{FEV}_{1}$ values. However, by means of a short training course, the GPs' use of spirometry for their patients with peripheral airways disease increased by six-fold.

Exclusive to this study is the training of all of the office staff. Apart from a short item on the programme (on the interpretation of spirometry tracings by the doctors - which lasted 30 minutes to an hour) the participants all had lessons in common. The aim of this was to emphasise the importance of teamwork in the handling of patients with COPD.

The course was conducted by the local hospital pulmonologist, but in every other respects it had a decentralised design. All sessions took place in the local community, and the spirometry instruction was run at the participants' own workplace.

Only one single type of spirometry equipment was used during the study, therefore simplifying the spirometry instruction session.

The present study measures neither the quality of spirometry performance nor the physicians' ability regarding diagnostic interpretation, and few data are available on this in the literature. Achieving good quality spirometry and making it widely available in primary health care would seem to be a great and difficult task. There is a need for further studies, especially on different sorts of training strategies. 


\section{Acknowledgement}

Funding for this study was provided by a study grant from the Norwegian Medical Association and by a donation from the Narvik division of the Norwegian Heart and Lung Patient Organisation.

\section{Conflicts of interest}

None declared.

\section{References}

1. Petty TL. Scope of the COPD problem in North America: early studies of prevalence and NHANES III data: basis for early identification and intervention. Chest 2000;117(5 Suppl 2):326S-31S.
2. Mannino DM, Etzel RA, Flanders WD. Do the medical history and physical examination predict low lung function? Arch Intern Med 1993;153(16):1892-7.

3. Buffels J, Degryse J, Heyrman J, Decramer M. Office spirometry significantly improves early detection of COPD in general practice: the DIDASCO Study. Chest 2004; 125(4):1394-9.

4. Burton DL, McKenzie G, Comino E. Asthma management in young adults in rural NSW. Respirology 1999;4(Suppl.):A5.

5. BTS guidelines for the management of chronic obstructive pulmonary disease. The COPD Guidelines Group of the Standards of Care Committee of the BTS. Thorax 1997;52 (Suppl 5):S1-28.

6. Standardization of Spirometry, 1994 Update. American Thoracic Society. Am J Respir Crit Care Med 1995; 152(3):1107-36.

7. Kroniske sykdommer i nedre luftveier (J40-J47). In: ICD-10: den internasjonale statistiske klassifikasjonen av sykdommer og beslektede helseproblemer : systematisk del og alfabetisk indeks. Oslo: Elanders forl.; 1998, p.508-12.

Available online at http://www.thepcrj.org 